\title{
Empirical Study on Influential Factors of Industry-education-research Synergetic Innovation Capability
}

\author{
Guan-Lin Wu, Yu Qian, Xin-Bo Sun, Hao-Tong Zhao \\ ${ }^{1}$ School of Business Administration, Northeastern University No. 11 Lane 3, Wenhua Road, Heping \\ District, Shenyang City, Liaoning Province, 110819, P. R. CHINA \\ neuglwu@126.com
}

Keywords: Colleges and universities, Industry-education-research (IER) synergetic innovation, Capability, Empirical study.

\begin{abstract}
This paper classifies the influential factors of industry-education-research (IER) synergetic innovation capability in colleges and universities into environmental exogenous pull, organizational endogenous push and innovation network control, which contain the second-level factors respectively, and builds a structural equation model containing these factors from the perspective of the system. The relevant data are collected through questionnaire survey and analyzed by confirmatory factor analysis method. The results show that the structural equation model is valid and that there exists high correlation between factor constructs. This study provides a reference for the improvement of IER synergetic innovation capability in Chinese colleges and universities.
\end{abstract}

\section{Introduction}

Actively promoting the synergetic innovation and continuing to deepen cooperation between colleges, universities and enterprises, research institutes is an important way for China to realize independent innovation and build an innovative country. The IER Developing Project organized and implemented jointly by the State Economic and Trade Commission, Ministry of Education and Chinese Academy of Sciences in 1992 has brought about a lot of research on reasons and influential factors of IER cooperation. The IER synergetic innovation capability in Chinese colleges and universities still remains to be improved at present. The internal and external factors of some innovation subjects play different roles in the synergetic innovation performance. Hence, the research on influential factors of IER synergetic innovation capability in colleges and universities has great theoretical significance and practical value on the improvement of the synergetic innovation capability.

This paper summarizes the influential factors of IER synergetic innovation capability in colleges and universities through theoretical review and then designs theoretical model and conducts questionnaire survey and empirical analysis in order to provide reference for improvement of IER synergetic innovation capability in colleges and universities.

\section{Theoretical Review and Research Hypothesis}

Combining the results of research on driving forces of IER synergetic innovation capability evolution by Shi Chengqi[1] and research on relationship and process of IER synergetic innovation in colleges and universities by Michael Fritsch[2] and Santoro, Saparito[3], this paper proposes the hypothesis related to IER synergetic innovation capability in colleges and universities from perspectives of environmental exogenous pull, organizational endogenous push and innovation network control and puts forward 8 factors of IER synergetic innovation capability in colleges and universities, including market environment, cultural environment, policy environment, organization management mechanism, organization incentive mechanism, power network, relationship network and exchange network on this basis.

\section{Environmental Exogenous Pull}

$\mathrm{Wu}$ Yue and $\mathrm{Gu}$ Xin point out that market and culture are the key environmental factors 
influencing both the IER synergetic innovation and the knowledge collaboration[4]. Through research on the main modes and characteristics of IER synergetic innovation in U.S., Lan Xiaoxia points out that improving the relevant laws and regulations as well as the policy guarantee system can motivate the enterprises and colleges of China to participate in the IER cooperation truly for long term[5]. Therefore, this part discusses the influential factors of IER synergetic innovation capability in colleges and universities, which are classified into market, cultural and policy environment.

Market Environment. According to the analysis on dynamic mechanism and existing problems of college-dominated synergetic innovation, Li Zuchao and Liang Chunxiao point put that the market pull is one of the dynamic factors of the college-dominated synergetic innovation and that the colleges should have not only research strength, but also marketing strength in respect of market forecasting and product sales[6]. Zhou Zheng, Yin Lingna and Cai Bing point out that the pull of market demand and pressure of market competition are the important dynamic factors inspiring the IER synergetic innovation[7].

Cultural Environment. Li Zhongyun and Deng Xiuxin point out that the units participating in synergetic innovation have different goals. Sometimes, the colleges want achievements in scientific research, the enterprises pursue economic benefits and the local governments require GDP growth. It is difficult for them to collaborate with each other because of their different ideas[8]. Stanley E. Fawcett, Stephen L. Jones and Amydee M. Fawcett point out that trust is the core of synergetic innovation capability and that the synergetic innovation driven by trust can improve the organization's ability required in this era of intense changes[9]. Based on the research about the dynamic evolution of IER cooperation relations, Plewa $\mathrm{C}$ and Quester P point out that trust, commitment and interaction have lasting effect on cooperative performance[10]. Li Hongxiu points out that the teachers of science and engineering are used to scientific experiments and technological innovation. They stress the accuracy of scientific data and uniqueness of research conclusions. However, the teachers of humanities and social sciences are accustomed to literature research and particular about the speculativeness of research and multi-dimensions of research conclusions. The disciplinary culture difference in academic language, thinking mode and research method causes trouble for colleges to conduct interdisciplinary synergetic innovation[11]. Zhang Lina and Tan Zhanglu point out that sufficient knowledge sharing and transfer among different innovation subjects will make the subjects of intellectual property rights lose the exclusivity of their intellectual property. Hence, the innovation subjects conceal a part of core technology, knowledge and information during synergetic innovation in order to protect their intellectual property. As a result, the synergetic cooperation cannot be conducted efficiently[12]. The research carried out by Isaksen I.S.A., Behrens H.L. and Brett P.O. finds that the organizational innovation climate not only interacts with personal innovation capability, but also affects the innovation performance by influencing individual mental process[13].

Policy Environment. The study of the US National Science Foundation suggests that High-tech industries can shorten the cycle of transformation of scientific and technological achievement into new product, if government increases financial support to them[14]. ShyuJ.Z. points out that the government's various innovation policy tools, such as a public plan, technology and education, financial and tax policy as well as laws have great effect on the demands and modes of the IER synergetic innovation in colleges and universities[15].

In conclusion, the IER synergetic innovation capability in colleges and universities can be investigated in respects of market environment, cultural environment and policy environment. It relates directly to the influence of environmental exogenous pull on the IER synergetic innovation capability in colleges and universities. Based on the above analysis, this paper proposes the following hypothesis:

HA: Environmental exogenous pull has a positive correlation to the IER synergetic innovation capability in colleges and universities.

H1: Market environment has a positive correlation to environmental exogenous pull.

$\mathrm{H} 2$ : Cultural environment has a positive correlation to environmental exogenous pull. 
H3: Policy environment has a positive correlation to environmental exogenous pull.

\section{Organizational Endogenous Push}

This part analyzes the influential factors of IER synergetic innovation capability in colleges and universities from the standpoint of organization construction, which are summed up as organization management mechanism and organization incentive mechanism.

Organization Management Mechanism. Liu Sheng, et al. propose that to explore management mechanism, policy guidance and basic market allocation for synergetic innovation, to establish synergetic management institution involving numerous collaborative subjects under the principle of normalization, integration, convenience and high efficiency, to specify the function and power of all parties and the ownership of personnel, resources, achievements and intellectual property, to take charge of negotiation and decision making on important issues, and to realize information communication, group coordination and mutual monitoring are the system and mechanism that the colleges must adopt[16]. In terms of the internal management mechanism, the internal governance structure, academic organization framework and the personnel management system of the colleges and universities will affect the IER synergetic innovation. To optimize the internal governance structure and establish board system can directly promote the IER synergetic innovation [17].

Organization incentive mechanism. The supporting theories of IER synergetic innovation in colleges and universities include motivation theory, transaction cost theory and triple helix theory. Since the desire of creation, work attitude and innovative achievement of knowledge creators in colleges and research institutions and R\&D personnel of enterprises are affected and restrained by various factors, we have to establish an internal incentive mechanism which can stimulate the human capital innovationenthusiasm so as to promote the technological innovation of the IER synergetic innovation alliance[18]. Xu Li points out that the motivation theory refers to how to mobilize the work enthusiasm of people to achieve the organizational goals. In order to obtain further development of IER synergetic innovation, the colleges must adopt motivation the ory and establish reasonable incentive mechanism to make all parties benefit from it[19]. The incentive mechanism of IER synergetic innovation in colleges and universities aims at enhancing the synergetic innovation efficiency by inspiring the positive factors in the organization to play a role through sharing and allocation system. Chen Yu emphasizes in which the right of claim for reward and remuneration mainly refers to one way that an individual or other subjects participating in the IER synergetic innovation share the achievements of intellectual property of IER synergetic innovation, and also an integral part of incentive mechanism of IER synergetic innovation[20]. Organizations participating in the IER synergetic innovation shall participate in the distribution of profit in accordance with their contribution in the innovation process, so as to inspire the organization personnel and cooperative agencies to make technological innovation. Li Jingjing proposes that the information sharing incentive is conducive to the efficient information exchange between members. The complete sharing of information is conductive to improving the utilization rate of technical knowledge. The building of information sharing incentive mechanism is helpful to encourage the cooperation subjects to obtain the information they need more quickly. This can improve the cooperation satisfaction greatly and establish trust among the internal employees to make them work hard [21].

In conclusion, the IER synergetic innovation capability in colleges and universities can be investigated in respects of organization management mechanism and organization incentive mechanism, which affect the IER synergetic innovation capability in colleges and universities through organizational endogenous push. Based on the above analysis, this paper proposes the following hypothesis

HB: The organizational endogenous push has positive correlation with the IER synergetic innovation capability in colleges and universities;

H4: The organization management mechanism has positive correlation with organizational endogenous push; 
H5: The organization incentive mechanism has positive correlation with organizational endogenous push.

\section{Innovation Network Control}

Hakansson $\mathrm{H}$ points out in the research that, once the structure of innovation network is formed, the evolved path dependence would restrict the IER synergetic innovation capability[22]. Kilduff $\mathrm{M}$ and W. Tsai find that allocation of power can effectively control the innovation network and then further improve the synergetic innovation capability[23]. Therefore, this part studies the factors affecting the IER synergetic innovation capability in colleges and universities from the perspectives of inter-organizational relationship and network, and reduces the factors to power network, exchange network and relationship network.

Power Network. Liu Wenbin et.al. find in the study that, though inequality relation often exists in innovation networks, most relative researches are based on the equality of all participating parties of IER synergetic innovation in colleges and universities[24]. The research carried out by Brenner T. $\mathrm{U}$, Cantner, and H. Graf et.al. also indicates that there's hierarchical structure in IER synergetic innovation. And the power is the important factor for cooperation and coordination[25]. Wong $S$ et.al. point out that the knowledge difference in IER synergetic innovation is the important factor resulting in power difference[26]. MARA-VALENTIN et al. find the affect of power status on transfer of rights and interests from the study on synergetic innovation subject market[27]. Dhanaraj points out that in order to guarantee the creation and acquisition of value in the IER synergetic innovation network, it is not necessary to depend on authority hierarchy. The core enterprises may coordinate the innovation network by coordinating transferability of knowledge, exclusiveness of innovation, and stability of network[28]. Thus to further realize "network governance".

Exchange Network. GREVESEN points out that one of the very important functions of the IER synergetic innovation is to realize inter-organizational knowledge transfer and sharing. Therefore, whether the information and knowledge can be fluently and rapidly transferred among all cooperative members or not is the key to the success of cooperative innovation[29]. SANTORO's research finds that relation credit is beneficial to knowledge sharing and transfer. And the knowledge sharing has strong positive correlation with synergetic innovation capability[30]. Besides, WILLIAMSON points out that the forming of exchange network has become a kind of choice of governance structure. In the term of transaction costs, it is of economical rationality and efficiency [31]. Michael Fritsch's empirical research on 300 German synergetic innovation network enterprises also proves its remarkable benefit and influence[32].

Relationship Network. GUALTI points out that the actor of close relationship may develop common cognition to certain behavior in social contact and further affect the behavior. Therefore, participants of synergetic innovation network can form social network by wide contact to affect the IER synergetic innovation capability[33]. By emphasizing different information advantages endowed by social network and emphasizing control power benefit obtained by actor from the advantage status in society, the network structure can be analyzed and divided into relationship and network level. Huo Yunfu and Chen Xinyue emphasize the contact among the parties, and divide the behavior actor contacts into different forms, including trading form (formal relationship based on commercial opportunities, such as subcontract relation and strategic alliance, etc.) and relation form (based on non-official social relations, such as entrepreneur industrial association membership and friendship, etc.)[34]; Besides, Yi Ming also points out that relational governance by competitive and cooperative interaction is positive to improvement of synergetic innovation capability[35].

To sum up, this study proposes the following hypothesis:

HC: Innovation network control has positive correlation with IER synergetic innovation capability;

H6: Power network has positive correlation with innovation network control;

H7: Exchange network has positive correlation with innovation network control;

H8: Relationship network has positive correlation with innovation network control. 


\section{Study Design}

\section{Theoretical Model}

Based on the above analysis, the study frame of this paper is determined as shown in Fig. 1. The influential factors of IER synergetic innovation capability colleges and universities are studied from the respects of environmental exogenous pull, organizational endogenous push and innovation network control.

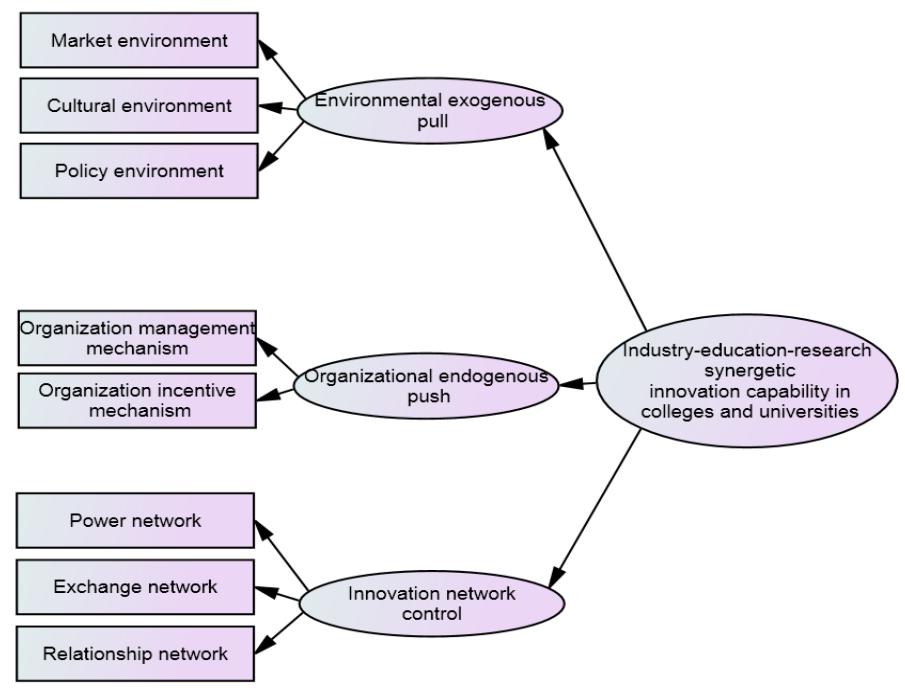

Fig.1 Theoretical Model

\section{Sampling and Data Collection}

Samples selected in this study include: enterprise personnel, college and university teachers and personnel, and users having certain knowledge about IER synergetic innovation of colleges and universities. Diversity and otherness of investigation objects help to avoid limitations of study findings and make the research conclusions more applicable.

In this study, the questionnaires are distributed on www.sojump.com. Compared with traditional mail or fax investigation, on-line investigation is featured by lower cost, wider investigation range, less distribution warp, and faster reply[36]. 280 copies of questionnaires are distributed in total. Eliminating those 27 copies with most similar answers for all questions, or multiple unfilled questions, the final effective questionnaires amount to 253 , which reaches $90.4 \%$ effective questionnaire collection rate. The investigation period started in the beginning of July 2014 and ended in the end of September of 2014.

This questionnaire includes 4 parts: Part-I specifies the tenet of this questionnaire; Part-II briefly introduces the concept and function of video open class; Part-III shows the scales of seven variables, including 22 questions which are all adopted with 5 grades Likert scale for measurement (1 represents very disagree, 5 represents very agree); and Part-IV is the end of this questionnaire, expressing thanks to questionnaire participants.

\section{Description of Variables}

Market Environment. This paper designs 2 questions, including market demand and market competition according to the study and analysis on the dynamic mechanism of IER synergetic 
innovation in colleges and universities carried out by Li Zuchao and Liang Chunxiao[6].

Culture Environment. In accordance with the analysis of Li Zhongyun, Deng Xiuxin[8], Plewa C, Quester P[10], and Li Hongxiu[11] on cultural factors of IER synergetic innovation capability in colleges and universities, this paper designs 2 questions mainly concerning credit and knowledge IPRs conflicts, etc.

Policy Environment. According to the analysis of Shyu J.Z et.al.[15] on political factors of IER synergetic innovation capability in colleges and universities, this paper designs 2 questions on policy environment mainly concerning strategic plan and legal guarantee, etc.

Organization Management Mechanism. According to the analysis and study of Zhang Haibin[17] on organization management mechanism, 2 questions are obtained by summary mainly concerning internal governance structure, academic organization frame and personnel management system.

Incentive Mechanism. According to the study on incentive mechanism and theory of Chen $\mathrm{Yu}[20]$ and Li Jingjing[21], et.al., and by the analysis on inter-organizational benefit relation and resource sharing rate, this paper proposes 2 questions about incentive mechanism mainly concerning information sharing system and remuneration incentive mechanism.

Power network. According to the study and analysis of Wong[26] et al. on power network, we perform measurement according to the features and structure of the power network. And this paper also proposes 2 questions mainly concerning rights and interests control and network governance in power network

Exchange Network. According to the study of GREVESEN[29], SANTORO[30], and WILLIAMSON[31] et al. on exchange network factors, this paper designs 2 questions on exchange network factors concerning resource transfer and transaction costs.

Relationship network. According to the study of Huo Yunfu, Chen Xinyue[34], and Yi Ming[35] et al. on relationship network, this paper designs 2 questions by mainly considering the affect of the relationship network on IER synergetic innovation capability in colleges and universities, as well as the existing references. The questions mainly concern network modes: trading mode and relation mode, plane mode and network mode, and effect of relational governance.

\section{Empirical Analysis}

\section{Reliability Analysis}

Reliability analysis for the scales is performed by adopting SPSS 19.0. And the result shows that the Cronbach's value of the whole scales is 0.901. And Cronbach's values of all dimensions are larger than 0.8 , which proves that the scales of this study are of good reliability.

Validity Analysis

Tab. 1 Fix Index in Confirmatory Factor Analysis

\begin{tabular}{|c|c|c|c|c|c|c|c|c|}
\hline \multirow{2}{*}{$\begin{array}{c}\text { Inspectio } \\
\mathrm{n} \\
\text { Statistics }\end{array}$} & \multicolumn{4}{|c|}{ Absolute Fit Index } & \multicolumn{4}{c|}{ Relative Fit Index } \\
\cline { 2 - 9 } & F & GFI & RMR & $\begin{array}{c}\text { RMSE } \\
\text { A }\end{array}$ & IFI & NFI & CFI & TLI \\
\hline $\begin{array}{c}\text { Actual } \\
\text { Results }\end{array}$ & 1.777 & 0.912 & 0.031 & 0.055 & 0.910 & 0.816 & 0.908 & 0.891 \\
\hline $\begin{array}{c}\text { Recomm } \\
\text { ended } \\
\text { Range }\end{array}$ & $<2$ & $>0.9$ & $<0.05$ & $<0.05$ & $>0.9$ & $>0.9$ & $>0.9$ & $>0.9$ \\
\hline
\end{tabular}

Most scales used in this study come from the mature scales of past references. Before finally confirming the scales, we also consulted to experts of relative fields, performed pre-investigation, and modified partial content of the scales which make the questionnaire have good content validity. The Amos 20.0 is adopted to perform confirmatory factor analysis to measure the structure validity 
of the scales. The result of Phase-I confirmatory analysis model shows that, most of the fit indexes are within the recommended range, but the NFI value is no ideal. However, this is acceptable. Researchers in the past found that, in circumstance of small sample and big freedom, for a hypothesis model with ideal fit, it might underestimate the model fit by using NFI value. Therefore, the fit of this model is of good condition and meets the theoretical frame proposed in this paper.

\section{Hypothesis Testing}

Amos 20.0 software is adopted in this study for building of structural equation model to check the proposed hypothesis and theoretical model. It is independent variable. The video open class quality is dependent variable. Market environment $1 \sim$ relationship network $2 \sim$ are observable variables. And e1 e19 are residual variables. The drawing result is as shown in Figure 3. And the inspection result is as shown in Table-2.

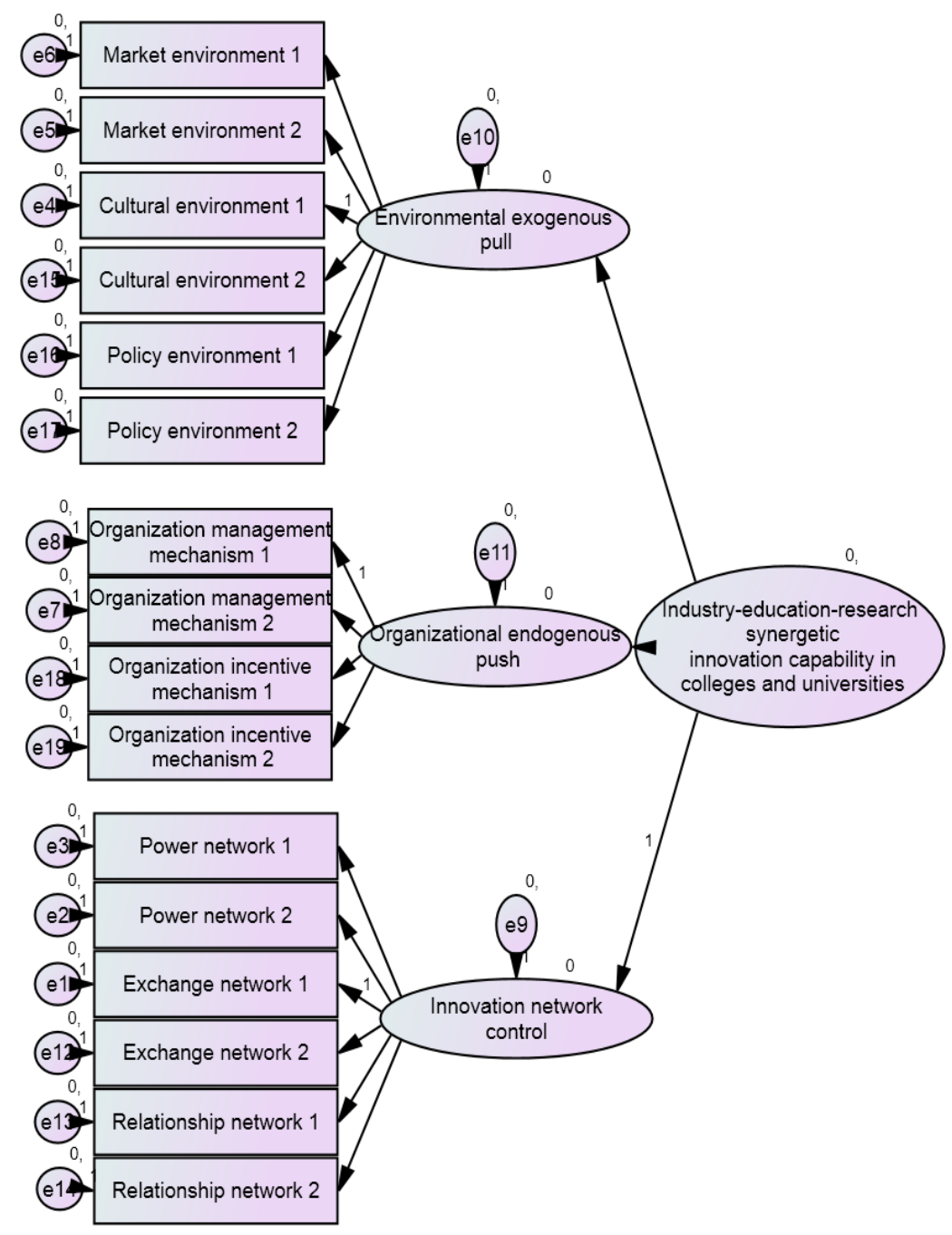

Fig. 2 Model Parameter Estimates

It can be seen from Fig. 2 that, environmental exogenous pull has obvious positive effect on IER synergetic innovation capability in colleges and universities (path coefficient $0.846>0.45$. $\mathrm{P}<0.001$ ), and the hypothesis HA is validated; market environment 1 has obvious positive effect on environmental exogenous pull (path coefficient $0.597>0.45, \mathrm{P}<0.001$ ), market environment 2 has obvious positive effect on environmental exogenous pull (path coefficient $0.500>0.45, \mathrm{P}<0.001$ ), and hypothesis $\mathrm{H} 1$ is validated; cultural environment 1 has no obvious positive effect on environmental exogenous pull (path coefficient $0.266<0.45, \mathrm{P}<0.001$ ), cultural environment 2 has no obvious positive effect on environmental exogenous pull (path coefficient $0.307<0.45, \mathrm{P}<0.001$ ), 
and hypothesis $\mathrm{H} 2$ is not validated; policy environment 1 has obvious positive effect on environmental exogenous pull (path coefficient $0.624>0.45, \mathrm{P}<0.001$ ), policy environment 2 has obvious positive effect on environmental exogenous pull (path coefficient $0.600>0.45, \mathrm{P}<0.001$ ), and hypothesis $\mathrm{H} 3$ is validated;

Tab. 2 SEM Path Coefficient and Hypothesis Testing

\begin{tabular}{|c|c|c|c|}
\hline Relationship Among Variables & $\begin{array}{c}\text { Standardized } \\
\text { Path Coefficient }\end{array}$ & $\begin{array}{l}\text { Correspondin } \\
\text { g Hypothesis }\end{array}$ & $\begin{array}{c}\text { Hypothesis } \\
\text { Testing Results }\end{array}$ \\
\hline $\begin{array}{c}\text { Environmental exogenous pull } \rightarrow \text { IER } \\
\text { synergetic innovation capability in } \\
\text { colleges and universities }\end{array}$ & 0.961 & HA & Supported \\
\hline $\begin{array}{l}\text { Market environment } 1 \text { and } 2 \rightarrow \\
\text { Environmental exogenous pull }\end{array}$ & $0.597 、 0.500$ & $\mathrm{H} 1$ & Supported \\
\hline $\begin{array}{l}\text { Cultural environment } 1 \text { and } 2 \rightarrow \\
\text { Environmental exogenous pull }\end{array}$ & $0.266 、 0.307$ & $\mathrm{H} 2$ & Unsupported \\
\hline $\begin{array}{l}\text { Policy environment } 1 \text { and } 2 \rightarrow \\
\text { Environmental exogenous pull }\end{array}$ & $0.624 、 0.600$ & $\mathrm{H} 3$ & Supported \\
\hline $\begin{array}{l}\text { Organizational endogenous push } \rightarrow \text { IER } \\
\text { synergetic innovation capability in } \\
\text { colleges and universities }\end{array}$ & 0.979 & HB & Supported \\
\hline $\begin{array}{c}\text { Organization management mechanism } 1 \\
\text { and } 2 \rightarrow \text { Organizational endogenous } \\
\text { push }\end{array}$ & $0.531 、 0.632$ & $\mathrm{H} 4$ & Supported \\
\hline $\begin{array}{l}\text { Organization incentive mechanism } 1 \text { and } \\
2 \rightarrow \text { Organizational endogenous push }\end{array}$ & $0.724 、 0.607$ & H5 & Supported \\
\hline $\begin{array}{l}\text { Innovation network control } \rightarrow \text { IER } \\
\text { synergetic innovation capability in } \\
\text { colleges and universities }\end{array}$ & 0.846 & $\mathrm{HC}$ & Supported \\
\hline $\begin{array}{c}\text { Power network } 1 \text { and } 2 \rightarrow \text { Innovation } \\
\text { network control }\end{array}$ & $0.277,0.328$ & H6 & Unsupported \\
\hline $\begin{array}{l}\text { Exchange network } 1 \text { and } 2 \rightarrow \\
\text { Innovation network control }\end{array}$ & $0.627,0.578$ & $\mathrm{H} 7$ & Supported \\
\hline $\begin{array}{l}\text { Relationship network } 1 \text { and } 2 \rightarrow \\
\text { Innovation network control }\end{array}$ & $0.568,0.528$ & $\mathrm{H} 8$ & Supported \\
\hline
\end{tabular}

The organizational endogenous push has obvious positive effect on IER synergetic innovation capability in colleges and universities (path coefficient $0.979>0.45$. $\mathrm{P}<0.001$ ), and the hypothesis $\mathrm{HB}$ is validated; organization management mechanism 1 has obvious positive effect on organizational endogenous push (path coefficient $0.531>0.45, \mathrm{P}<0.001$ ), organization management mechanism 2 has obvious positive effect on organizational endogenous push (path coefficient $0.632>0.45, \mathrm{P}<0.001$ ), and hypothesis $\mathrm{H} 4$ is validated; organization incentive mechanism 1 has obvious positive effect on organizational endogenous push (path coefficient $0.724<0.45, \mathrm{P}<0.001$ ), organization management system 2 has obvious positive effect on organizational endogenous push (path coefficient $0.607<0.45, \mathrm{P}<0.001$ ), and hypothesis $\mathrm{H} 5$ is validated.

The innovation network control has obvious positive effect on IER synergetic innovation capability in colleges and universities (path coefficient $0.846>0.45$. $\mathrm{P}<0.001$ ), and the hypothesis $\mathrm{HC}$ is validated; power network 1 has no obvious positive effect on innovation network control (path coefficient $0.277<0.45, \mathrm{P}<0.001$ ), power network 2 has no obvious positive effect on innovation network control (path coefficient $0.328<0.45, \mathrm{P}<0.001$ ), and hypothesis $\mathrm{H} 6$ is not validated; exchange network 1 has obvious positive effect on innovation network control (path coefficient $0.627>0.45, \mathrm{P}<0.001$ ), exchange network 2 has obvious positive effect on innovation 
network control (path coefficient $0.578>0.45, \mathrm{P}<0.001$ ), and hypothesis $\mathrm{H} 7$ is validated; relationship network 1 has obvious positive effect on innovation network control (path coefficient $0.568>0.45, \mathrm{P}<0.001$ ), relationship network 2 has obvious positive effect on innovation network control (path coefficient $0.528>0.45, \mathrm{P}<0.001$ ), and hypothesis $\mathrm{H} 8$ is validated.

\section{Main Research Results and Englishtenments}

This study analyzes and tests the IER synergetic innovation capability in colleges and universities. On the basis of the previous literature, this paper summarizes the influential factors as environmental exogenous pull, organizational endogenous push and innovation network control and further puts forward the second-level factors, including market environment, cultural environment, policy environment, organization management mechanism, incentive mechanism, power network, relationship network and exchange network.

The results of empirical research on the structural equation model indicates that the influential factors of IER synergetic innovation capability in colleges and universities consist of environmental exogenous pull, organizational endogenous push and innovation network control and that all the second-level influential factors are supported except for cultural environment and power network.

The reason why the cultural environment and power network cannot be supported may be that the colleges are more inclined to choose the subjects whose status and culture are similar to theirs when they look for partners of IER synergetic innovation. Therefore, the path coefficients of cultural environment and power network are small.

Specifically, the environmental exogenous pull affects the IER synergetic innovation capability in colleges and universities. The colleges should pay attention to the market demand change while enhancing their scientific research strength so as to make their research direction geared to the market demand. Secondly, the colleges should create an atmosphere of coordinate the thoughts of encouraging communication and innovation and tolerating failure through coordination of the innovation subjects. Meanwhile, the national government should give more policy support to the IER synergetic innovation in colleges and universities so as to propel the deepening of synergetic cooperation and improvement of synergetic innovation mode continuously.

The organizational endogenous push plays an important role in the improvement of IER synergetic innovation capability in colleges and universities. The colleges should discover the problems hindering further synergetic innovation in organization mechanism in time, continuously improve the organization management mechanism, specify the function and power of the parties to the synergetic innovation as well as the ownership of personnel, resources, achievements and intellectual property, and also establish incentive mechanism covering the whole synergetic innovation process, so as to achieve the goal of balancing the interests of all parties and bringing the staff's initiative into full play.

The innovation network control is an important influential factor of the IER synergetic innovation capability in colleges and universities. The colleges should weaken the authority hierarchy and lay emphasis on equal relationship between the parties to synergetic innovation. Secondly, the colleges should promote the knowledge and information exchange and flow among the synergetic innovation subjects so as to increase the degree of knowledge and information sharing. At the same time, the colleges should continuously expand the social network of synergetic innovation subjects formed through social contact and obtain resource advantage through interaction with social forces.

There are some limitations in this paper. For example, the number of samples is limited. There is no in-depth discussion on the relationship among environmental exogenous pull, organizational endogenous push and innovation network control. We will conduct a further research on the influential factors of IER synergetic innovation capability in colleges and universities.

\section{Acknowledgement}

This paper is sponsored by the project of Twelve-five Planning of Liaoning provincial education 
and science of China of 2013 (JG13DB002).

\section{Reference}

[1] Shi Chengqi, Dang Xinghua. Driving Forces of the Innovation Network Evolution[J]. Forum on Science and Technology in China, 2013(1):5-10.

[2] MICHAEL FRITSCH, MARTINA KAUFFELD - MONZ. The Impact of Network Structure on Knowledge Tranefer: An Application of Social Network Analysis in the Context of Regional Innovation Networks [J]. The Annals of Regional Science, 2010,44(1):21-38.

[3] SANTORO M D, SAPARITO P A. Self-interest assumption and relational trust in university-industry knowledge transfers [J]. LEEE Transactions on Engineering Management, 2006,53(3):335-347.

[4] Wu Yue, Gu Xin. Study on Knowledge Collaboration Process of Industry-Education-Research Synergetic Innovation [J]. Forum on Science and Technology in China, 2012(10):21.

[5] Lan Xiaoxia, Main Modes, Characteristics and Enlightenments of Industry-Education-Research Synergetic Innovation in U.S. [J]. China Higher Education Research, 2014(4):50-53.

[6] Li Zuchao, Liang Xiaochun. Exploration and Analysis on Synergetic Innovation Mechanismfrom the Perspective of College Innovation Subject [J]. China Higher Education Research, 2012(7):82-83.

[7] Zhou Zheng, Yin Lingna, Cai Bing. Research on Dynamic Mechanism of Industry-Education-Research Synergetic Innovation in China [J]. Soft Science, 2013, 27(7):53.

[8] Li Zhongyun, Deng Xiuxin. Predicament, Path and Policy Suggestion of College Synergetic Innovation [J]. Chinese Higher Education, 2011, 17:12.

[9] Stanley E. Fawcett, Stephen L. Jones, Amydee M. Fawcett. Supply chain trust: The catalyst for collaborative innovation[J]. Business Horizons, 2012(55):163-178.

[10] Plewa C, Quester P. Key drivers of university-industry relationships: the role of organizational compatibility and personal experience[J].Journal of Services Marketing, 2007,21(5):370-382.

[11]Li Hongxiu. Cultural Conflict and Adjustment of College Synergetic Innovation [J]. Jiangsu Higher Education, 2013(5):29.

[12]Zhang Lina, Tan Zhanglu. Conflict Analysis between Synergetic Innovation and Intellectual Property [J]. Science and Technology Management Research, 2013(6):164.

[13] Isaksen I.S.A., Behrens H.L., Brett P.O. A historical reconstruction of ships' fuel consumption and emissions[J]. Journal of Geophysical Research.2007,112(D12):D12301.

[14]National Science Foundation. Small Business Technology Transfer Program[EB/OL].[2012-04-14]http://www.sba.gov/about-sba-services/7050\&rct=j\&sa=X\&ei=BcS MT_O6FOuOiAeR_MDFCQ\&ved=0CFsQ6QUoADAE\&q=STTR\&usg=AFQjCNECoJ1BLVyyeO -icAtMGN5qCvI4sQ.

[15] Shyu J.Z., et. A cross-national comparative analysis of innovation policy in the integrated circuit industry [J]. Technology in Society,2001,23(2):227-240.

[16]Liu Sheng, et al. Study on Industry-Education-Research Synergetic Innovation System in Colleges and Universities [J]. Platforms of Colleges and Universities, 2013(13):176-177.

[17]Zhang Haibin. Influential Factors and Mechanism Construction of Industry-Education-Research Synergetic Innovation in Colleges and Universities [J]. Journal of Fuzhou University (Philosophy and Social Science), 2013(3):104-107.

[18]Zhou Zheng, Yin Lingna, Cai Bing. Research on Dynamic Mechanism of 
Industry-Education-Research Synergetic Innovation in China [J]. Soft Science, 2013, 27(7):52-56.

[19] Xu Li, Yang Chenlu. Study on Organization Pattern and Operating Mechanism of Industry-Education-Research Synergetic Innovation [J]. Science Mosaic, 2012(11):210-214.

[20]Chen Yu. Study on Intellectual Property Interests Allocation System in Industry-Education-Research Synergetic Innovation [D]. Wuhan: Central China Normal University, 2013.

[21]Li Jingjing. Study on Operating Mechanism of Industry-Education-Research Synergetic Innovation [D]. Wuhan: Wuhan University of Technology, 2013.

[22]Hakansson H.. Industrial Technological Development: A Network Approach[M]. London: Croom Helm, 1987.

[23] Kilduff M. and W. Tsai. Social Networks and Organizations[M]. London: Sage,2003.

[24]Liu Wenbin, Tang Jie. Exploration on Source and Change of Power in Network Organization [J]. Journal of University of Electronic Science and Technology of China (Social Science Edition), 2009, 11(5):9-12.

[25]Brenner T., U. Cantner and H. Graf. Innovation networks: measurement, performance and regional dimensions[J]vation, 2011,18(1):1-5.

[26] Wong S. S., V. T. Ho and C. H. Lee. A power perspective to interunit knowledge transfer: linking knowledge attributes to unit power and the transfer of knowledge[J]. Journal of Management, 2008, 34(1): 127-150.

[27] MARA-VALENTIN E M, MONTORO-SANCHEZ A, GUERRAS-MARIN L A. Determining Factors in the Success of R\&D Cooperative Agreements between Firms and Research Organizations[J]. Research Policy, 2004,33(1):17-40.

[28]Pittaway L., R. Maxine, K. Munir, D. Denyer \& A. Neely. Networking and Innovation: A Systematic Review of the Evi-dence [J]. International Journal of Management Reviews, 2004,(5-6) : 137-168.

[29] GREVESEN C W, DAMANPOUR F. Performance implications of organisational structure and knowledge sharing in multinational $\mathrm{R} \& \mathrm{D}$ networks[J]. International Journal of Technology Management, 2007,38(1/2):1 13-136.

[30] SANTORO M D, SAPARITO P A. Self-interest assumption and relational trust in university. industry knowledge transfers[J]. LEEE Transactions on Engineering Management. 2006,53(3):335-347.

[31] WILLIAMSON O E. The Economic Institutions of Capitalism: Firms, Marekets, Relational Contracting[M], Free Press, 1985.

[32] MICHAEL FRITSCH, MARTINA KAUFFELD-MONZ .The Impact of Network on Knowledge Tranefer :An Application of Social Network Analysis in the Context of Regional Innovation Networks [J]. The Annals of Regional Science,2010,44(1):21-38.

[33] GUALTI R. Alliance and networks[J].Strategic Management Journal ,1998,19:293-317.

[34]Huo Yunfu, Chen Xinyue, Yang Deli, Dong Yizhe. Study on Enterprise Innovation Network [J]. Science of Science and Management of S\&T. 2002, 23(10):50-53.

[35] Yi Ming. Relationship, Interaction and Synergetic Innovation: Industrial Cluster Governance Logic_-From the Perspective of Cluster Residual [J]. Theory Monthly, 2010(8):166-169.

[36] Simsek Z, Veiga $\mathbf{J}$.A primer on Internet organizational surveys[J].Organizational Research Methods,2001,4(3):218-235. 